\title{
Antipsychotic Drug Use and Community-Acquired Pneumonia
}

\author{
Gianluca Trifirò
}

Published online: 11 March 2011

(C) The Author(s) 2011. This article is published with open access at Springerlink.com

\begin{abstract}
Antipsychotics are generally distinguished as atypical and typical agents, which are indicated in the treatment of acute and chronic psychoses and other psychiatric disorders. In April 2005, the US Food and Drug Administration issued a warning about the increased risk of all-cause mortality associated with atypical antipsychotic use in elderly patients with dementia. Pneumonia was one of the most frequently reported causes of death. The same warning was extended to typical antipsychotics in June 2008. In recent years, several observational studies have further explored the association between antipsychotic use, mainly in elderly patients, and the risk of fatal/nonfatal community-acquired pneumonia. The aim of this review is to revise and discuss the scientific evidence and biologic explanations for the association between atypical and typical antipsychotic use and pneumonia occurrence. Some general recommendations to clinicians are proposed to prevent the risk of pneumonia in patients requiring antipsychotic treatment.
\end{abstract}

Keywords Antipsychotic agents · Butyrophenones . Phenothiazines - Atypical antipsychotics · Pneumonia . Aspiration pneumonia $\cdot$ Aged $\cdot$ Drug toxicity

G. Trifirò $(\bowtie)$

Department of Medical Informatics, Erasmus University Medical Center,

Dr Molewaterplein 50, 3000 DR,

Rotterdam, The Netherlands

e-mail: g.trifiro@erasmusmc.nl

G. Trifirò

IRCCS Centro Neurolesi Bonino Pulejo,

Messina, Italy

\section{Introduction}

Antipsychotic drugs are generally categorized as typical antipsychotics (sometimes referred to as first-generation or conventional antipsychotics, or neuroleptics) and atypical antipsychotics; both are approved for the treatment of acute and chronic psychoses (ie, schizophrenia), mania, agitation, and other psychiatric disorders.

Typical antipsychotics were developed initially in the 1950s. Chlorpromazine was the first typical antipsychotic to enter clinical use. Atypical antipsychotics have been marketed since the 1990s, starting with clozapine, followed by risperidone and olanzapine, and more recently quetiapine, aripiprazole, ziprasidone, and paliperidone. The atypicality of this newer class consists of greater efficacy in the treatment of negative symptoms (ie, catatonia, apathy) of schizophrenia and lower risk of extrapyramidal adverse events, as compared to typical antipsychotics. Because of a supposed better safety profile, in the past decade, the use of atypical antipsychotics rapidly expanded worldwide, even for unlicensed indications of use, such as the treatment of behavioral and psychological symptoms of dementia [1].

A population-based study found that more than 3\% of community-dwelling patients are currently treated with antipsychotics in Italy, with a striking increase in the use of atypical antipsychotics over time [2•]. These findings are in accord with data from the United Kingdom [3] and United States, where olanzapine and risperidone were already the most commonly prescribed antipsychotic drugs in 1997 [4].

The increasing use of atypical antipsychotics has resulted in a growing number of safety alerts that were launched in the past few years by international regulatory agencies, especially regarding off-label use of atypical 
antipsychotics in elderly persons with dementia and related disorders [5••]. In April 2005, a warning was issued by the Food and Drug Administration (FDA) to inform health professionals about the results of a pooled analysis of 17 randomized clinical trials reporting a 1.7 times increased risk of all-cause mortality associated with atypical antipsychotic use in elderly patients with dementia [6]. Pneumonia was one of the most frequently reported causes of death. The FDA stated that at that point, an increased risk could not be excluded for typical antipsychotic drugs. In June 2008, the FDA extended the warning about the increased risk for all-cause mortality in elderly patients with dementia to typical antipsychotic drugs $[7 \bullet \bullet]$.

The mechanism behind the increase in mortality is not clear, and the question remains whether it is pneumonia that increases the risk for mortality in elderly patients receiving antipsychotic drugs. This question is not easy to assess, because the baseline risk for fatal pneumonia is already high in elderly patients with psychiatric diseases [8]. Nevertheless, several observational studies were recently conducted to specifically explore the association between the use of antipsychotics and the risk of fatal/nonfatal community-acquired pneumonia (CAP), mainly in cohorts

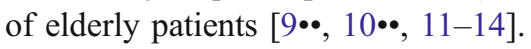

The aim of this review is to critically revise the current scientific evidence concerning the relationship between antipsychotic use and occurrence of CAP and to discuss the possible biologic explanations for such an association. Finally, recommendations are provided for clinicians who decide to prescribe antipsychotics.

\section{Epidemiologic Evidence}

All published articles investigating or citing antipsychoticrelated pneumonia were identified through a Medline search using the key words "antipsychotic agents" or the name of individual active substances (eg, olanzapine, risperidone, haloperidol) and "pneumonia." Among these articles, only five observational studies specifically investigated the risk of fatal/nonfatal pneumonia in association with antipsychotic use, as summarized in Table $1[9 \bullet \bullet, 10 \bullet \bullet$, 11-13].

Trifirò et al. [9••] conducted a population-based, casecontrol study nested in a cohort of 2560 Dutch communitydwelling elderly patients who were newly treated with antipsychotics from the general practice Integrated Primary Care Information (IPCI) database. Overall, 258 incident cases of pneumonia were identified in this cohort and matched to 1689 control participants on age, sex, and index date. Sixty-five $(25 \%)$ of the case patients died in 30 days, and pneumonia was judged fatal by the authors. Case patients were more likely to be housebound and to be affected by chronic obstructive pulmonary disease, diabetes mellitus, hypertension, heart failure, arrhythmia, or Parkinson disease. Current users of either atypical (adjusted odds ratio [adj. OR]: 2.61; 95\% CI: $1.48-4.61$ ) or typical (adj. OR: 1.76 ; 95\% CI: 1.22-2.53) antipsychotics were associated with a dose-dependent increase in the risk for pneumonia as compared to unexposed patients. Analyses of chemical subgroups of typical antipsychotic drugs showed some heterogeneity, with butyrophenones being associated with slightly increased risk for pneumonia, whereas phenothiazines were associated with a fourfold increased risk. Analysis of individual drugs was possible only for a few of the most frequently prescribed antipsychotics, and showed that the greatest pneumonia risk was associated with risperidone (adj. OR: 3.51; 95\% CI: 1.94-6.36).

In this study, the highest risk for pneumonia was observed during the first week of treatment, thus suggesting an acute effect of antipsychotics. The pneumonia risk was similarly increased in elderly patients with or without dementia.

Concerning fatal pneumonia specifically, only atypical antipsychotic drugs were associated with an increase in the risk (adj. OR: 5.97; 95\% CI: 1.49-23.98); however, this analysis was based on only seven exposed cases.

Overall, the conclusions from the study from Trifirò et al. [9••] are very much in accord with the main findings from another Dutch population-based, nested case-control study that was done using data from the PHARMO database [10••]. This study reported an increased risk for hospitalization due to pneumonia during the first week after the initiation of antipsychotic drug therapy, and especially with atypical agents (adj. OR: 3.1; 95\% CI: 1.9-5.1).

Similar findings also were observed in a case-control study of adults aged 65 years or older at a rural community hospital in Ohio (USA) during 2004 and 2006. The authors of this study explored the risk for pneumonia as cause of hospitalization with the use of atypical antipsychotics and other non-neuropsychiatric drug classes that were suspected to be possible risk factors for CAP [11]. As compared to patients unexposed to study drugs, users of atypical antipsychotics were associated with a significant increase in the risk for CAP (adj. OR: 2.26; 95\% CI: 1.23-4.15).

Interestingly, the same findings were observed in the study by Star et al. [12], which used a completely different methodology. These authors applied the pattern-discovery method for longitudinal patient records on the UK IMS Health Disease Analyzer dataset as of January 1, 2006 [12]. The method contrasted the observed rate of registration of pneumonia-related International Classification of Diseases (ICD)-10 terms in various time periods relative to the prescription of atypical and typical antipsychotics, to the overall registration rate of the same medical event, relative 
Table 1 List of observational studies that explored specifically the association between onset of fatal/nonfatal pneumonia and use of antipsychotic drugs

\begin{tabular}{|c|c|c|c|c|}
\hline $\begin{array}{l}\text { Study, journal, } \\
\text { year }\end{array}$ & $\begin{array}{l}\text { Study design, } \\
\text { population }\end{array}$ & Outcome & Exposure & Main findings \\
\hline \multirow[t]{2}{*}{$\begin{array}{l}\text { Trifirò et al. [9••], } \\
\text { Ann Intern } \\
\text { Med, } 2010\end{array}$} & \multirow[t]{2}{*}{$\begin{array}{l}\text { Case-control } \\
\text { nested in a } \\
\text { cohort of } \\
\text { elderly patients } \\
(\geq 65) \text { newly } \\
\text { treated with } \\
\text { antipsychotics } \\
\text { from the Dutch } \\
\text { general practice } \\
\text { database (IPCI) }\end{array}$} & \multirow[t]{2}{*}{$\begin{array}{l}\text { Fatal and nonfatal } \\
\text { community- } \\
\text { acquired } \\
\text { pneumonia }\end{array}$} & $\begin{array}{l}\text { According to the type of } \\
\text { antipsychotic being prescribed } \\
\text { before the onset of the event: } \\
\text { - atypical } \\
\text { - typical } \\
\text { - butyrophenones } \\
\text { - phenothiazines } \\
\text { - others (ie, benzamides) } \\
\text { - combination }\end{array}$ & $\begin{array}{l}\text { Fatal/nonfatal pneumonia: a) } \\
\text { current use of atypical vs past } \\
\text { use of any antipsychotics: adj. } \\
\text { OR=2.6 ( } 95 \% \text { CI: } 1.5-4.6) \text {; } \\
\text { b) current use of typicals vs } \\
\text { past use of any antipsychotics: } \\
\text { adj. OR=1.8 (95\% CI: } 1.2- \\
2.5) \text {; c) for both atypical and } \\
\text { typical antipsychotics, dose- } \\
\text { dependent increase in the risk. } \\
\text { Highest increase in risk } \\
\text { during first week of treatment. }\end{array}$ \\
\hline & & & $\begin{array}{l}\text { According to timing relative to event: } \\
\text { - current use } \\
\text { - past use }\end{array}$ & $\begin{array}{l}\text { Fatal pneumonia: a) current use } \\
\text { of atypical vs past use of any } \\
\text { antipsychotics: adj. OR=6.0 } \\
\text { (95\% CI: } 1.5-24.0) \text {. }\end{array}$ \\
\hline $\begin{array}{l}\text { Knol et al. }[10 \bullet \bullet] \\
\text { J Am Geriatr } \\
\text { Soc, } 2008\end{array}$ & $\begin{array}{l}\text { Case-control } \\
\text { nested in a } \\
\text { cohort of } \\
\text { elderly patients } \\
\text { ( } \geq 65) \text { newly } \\
\text { treated with } \\
\text { antipsychotics } \\
\text { from the Dutch } \\
\text { PHARMO } \\
\text { database, which } \\
\text { collates } \\
\text { information on } \\
\text { drug dispensing } \\
\text { and } \\
\text { hospitalization }\end{array}$ & $\begin{array}{l}\text { Hospital admission } \\
\text { due to pneumonia }\end{array}$ & $\begin{array}{l}\text { According to the type of antipsychotic } \\
\text { being dispensed prior to hospital } \\
\text { admission: } \\
\text { - atypical } \\
\text { - typical } \\
\text { - combination } \\
\text { According to timing relative to event: } \\
\text { - current use } \\
\text { - recent past use } \\
\text { - past use } \\
\text { - no use }\end{array}$ & $\begin{array}{l}\text { a) current use of atypical vs no } \\
\text { use of antipsychotics: adj. } \\
\text { OR=3.1 (95\% CI: } 1.9-5.1) \text {; } \\
\text { b) current use of typicals vs } \\
\text { no use of antipsychotics: adj. } \\
\text { OR=1.5 (95\% CI: } 1.2-1.9) ; \text { c) } \\
\text { highest increase in risk during } \\
\text { the first week of treatment } \\
\text { with atypical and typical } \\
\text { antipsychotics. }\end{array}$ \\
\hline $\begin{array}{l}\text { Gau et al. [11], } \\
\text { BMC Geriatrics, } \\
2010\end{array}$ & $\begin{array}{l}\text { Case-control } \\
\text { study of adults } \\
\text { aged } 65 \text { years or } \\
\text { older at a rural } \\
\text { community } \\
\text { hospital in the } \\
\text { state of Ohio } \\
\text { (USA) }\end{array}$ & $\begin{array}{l}\text { Hospital admission } \\
\text { due to community- } \\
\text { acquired } \\
\text { pneumonia with } \\
\text { radiographic } \\
\text { evidence }\end{array}$ & $\begin{array}{l}\text { According to the drug class } \\
\text { being dispensed prior } \\
\text { to hospital admission: } \\
\text { - atypical antipsychotics } \\
\text { - other drug classes (ie, } \\
\text { narcotics, proton pump } \\
\text { inhibitors, inhaled } \\
\text { corticosteroids, } \beta_{2} \text { agonist } \\
\text { bronchodilator, } \\
\text { anticholinergic } \\
\text { bronchodilator, iron } \\
\text { supplements, NSAIDs) }\end{array}$ & $\begin{array}{l}\text { Use of atypical antipsychotics } \\
\text { vs no use of any study drugs: } \\
\text { adj. OR=2.26 ( } 95 \% \text { CI: } 1.23- \\
4.15) \text {. }\end{array}$ \\
\hline $\begin{array}{l}\text { Star et al. [12], Br } \\
\text { J Gen Pract, } \\
2010\end{array}$ & $\begin{array}{l}\text { Self-controlled } \\
\text { cohort analysis } \\
\text { using electronic } \\
\text { medical records } \\
\text { of UK IMS } \\
\text { Health Disease } \\
\text { Analyzer } \\
\text { database }\end{array}$ & $\begin{array}{l}\text { Acute chest } \\
\text { infections, } \\
\text { bronchopneumonia, } \\
\text { hypostatic } \\
\text { pneumonia }\end{array}$ & $\begin{array}{l}\text { Distribution over time of } \\
\text { atypical and typical } \\
\text { antipsychotic prescriptions } \\
\text { with respect to date of } \\
\text { diagnosis of the study } \\
\text { outcomes }\end{array}$ & $\begin{array}{l}\text { In elderly patients }(\geq 65) \text { : a) } \\
\text { higher rate of acute } \\
\text { chest infections following } \\
\text { atypical and much less } \\
\text { typical antipsychotic } \\
\text { prescriptions; b) higher rate } \\
\text { of bronchopneumonia } \\
\text { following } \\
\text { either atypical or typical } \\
\text { antipsychotic prescriptions. } \\
\text { In younger } \\
\text { patients }(<65) \text { : a) no higher } \\
\text { rate of acute chest infections } \\
\text { following atypical } \\
\text { and much less typical }\end{array}$ \\
\hline
\end{tabular}


Table 1 (continued)

\begin{tabular}{|c|c|c|c|c|}
\hline $\begin{array}{l}\text { Study, journal, } \\
\text { year }\end{array}$ & $\begin{array}{l}\text { Study design, } \\
\text { population }\end{array}$ & Outcome & Exposure & Main findings \\
\hline $\begin{array}{l}\text { Barnett et al. [13], } \\
\text { J Clin } \\
\text { Psychopharmacol, } \\
2006\end{array}$ & $\begin{array}{l}\text { Retrospective } \\
\text { cohort study in } \\
\text { patients } \\
\text { hospitalized } \\
\text { due to pneumonia } \\
\text { from US Veterans } \\
\text { Administration } \\
\text { database }\end{array}$ & In-hospital mortality & $\begin{array}{l}\text { According to the type of } \\
\text { antipsychotic being } \\
\text { dispensed within } 120 \text { days } \\
\text { prior to hospital admission: } \\
\text { - atypical } \\
\text { - typical } \\
\text { - combination } \\
\text { Exposure to } \\
\text { antidepressants } \\
\text { and mood stabilizers was } \\
\text { also investigated }\end{array}$ & $\begin{array}{l}\text { antipsychotic prescriptions. } \\
\text { a) use of typical } \\
\text { antipsychotics vs no use of } \\
\text { neuropsychiatric drugs: adj. } \\
\text { OR }=1.5 \text { ( } 95 \% \text { CI: } 1.0-2.2 \text {; } \\
\text { b) use of atypical } \\
\text { antipsychotics vs no use of } \\
\text { neuropsychiatric drugs: adj. } \\
\text { OR }=1.2 \text { (95\% CI: } 1.0-1.5)\end{array}$ \\
\hline
\end{tabular}

Adj. OR — adjusted odds ratio; IPCI — Integrated Primary Care Information; NSAID—nonsteroidal anti-inflammatory drug.

to prescriptions of other drugs in the same data. In elderly patients, higher rates of acute chest infections and bronchopneumonia following atypical and, to a lesser extent, typical antipsychotic prescriptions were observed in this study.

Concerning the risk of pneumonia with antipsychotic use, two short reports also were recently published [13, 14].

Barnett et al. [13] presented a brief report on a study conducted using the US Veterans Administration database. They found a statistically significant increased risk for inhospital mortality only with recent exposure to typical antipsychotic drugs in patients hospitalized because of pneumonia. Different setting, aim, and methodology could explain the difference between this study and previously described studies. Finally, a small, incompletely reported study using Medicaid data [14] found no difference in the risk for hospitalization for pneumonia between current users of atypical and typical antipsychotic drugs. No comparison with unexposed patients was performed in this US study, which did not assess fatal/nonfatal pneumonia as primary outcome.

In addition to the observational studies, evidence about fatal pneumonia and pneumonia as a cause of treatment discontinuation in patients treated with antipsychotics has also emerged from randomized clinical trials $[6,7 \bullet \bullet, 15]$.

To summarize, all epidemiologic studies documented an increased risk of pneumonia in association with typical and atypical antipsychotic use exclusively in elderly patients, but no evidence exists about a similarly high risk in patients younger than 65 years. Future studies should explore if the increase in the risk of pneumonia is also observed in young/ adult patients, who are generally prescribed antipsychotics for completely different indications than the indications in the elderly. Moreover, most of the studies explored the effect of the atypical and typical antipsychotics classes as a whole. Because of relevant differences in the receptor binding profile across various antipsychotics, heterogeneity in the risk of pneumonia may be anticipated [16].

Among typical antipsychotics, a significantly higher risk for pneumonia with phenothiazines as compared to butyrophenones was observed in one of the observational studies. Therefore, the observed class effect of antipsychotics with respect to pneumonia risk should be interpreted cautiously $[9 \cdot \bullet]$.

Some epidemiologic issues that have been encountered in all the observational studies exploring the risk of pneumonia with antipsychotic use merit further discussion.

\section{Pneumonia Ascertainment in Healthcare Databases}

All the observational studies identified newly diagnosed CAP as the study outcome. The studies that were carried out using data from claims databases could capture only pneumonia as cause of hospitalization $[10 \bullet, 11,13,14]$, whereas all the potential cases of CAP could be ascertained in the study conducted though

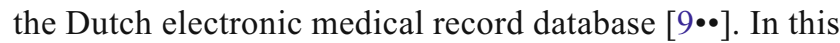
study, pneumonia was ascertained through a two-step approach. First, a broad search within diagnostic codes and narrative was undertaken. Subsequently, all the identified potential cases were independently validated through manual inspection of medical records by two researchers, who were blinded to the exposure status. The two assessors could classify the potential pneumonia cases as definite (either confirmed by specialist or diagnosed by chest radiography), possible (diagnosed by general practitioners on the basis of respiratory signs and symptoms), or non-cases. 
This strategy allowed for a more precise identification of the start of the disease corresponding to the first manifestation of clinical signs and symptoms that may be related to pneumonia (ie, fever, dyspnea, and other respiratory signs and symptoms).

Overall, Trifirò et al. [9••] reported that only 56 of 258 case patients $(22 \%)$ were hospitalized for pneumonia, thus supporting the idea that studies conducted in claims databases may not be able to identify most of the pneumonia cases occurring in community-dwelling persons.

\section{Confounding by Indication}

"Confounding by indication" is a commonly used term that refers to an extraneous determinant of the outcome parameter that is present if a perceived high risk or poor prognosis is an indication for intervention. The indication is a confounder because it correlates with the intervention and is a risk indicator for the illness [17]. Confounding by indication is likely in the association between antipsychotic drugs and new onset of pneumonia, because the choice of the antipsychotic drug is often associated with the prognosis or condition of a patient, which in itself can be a risk factor for fatal/nonfatal pneumonia. Behavioral and psychotic symptoms requiring antipsychotic treatment may be predictors of mortality in older demented patients [18]. As a consequence, confounding by indication should be controlled for, when assessing the risk of fatal pneumonia in elderly patients treated with antipsychotics as compared to non-users. For this reason, in the two Dutch investigations, the study population was restricted to new users of antipsychotic drugs only $[9 \bullet \bullet, 10]$. Yet, atypical antipsychotic drugs seem to be prescribed to less healthier patients in comparison to typical antipsychotic drugs, because of the supposed better safety profile [19]. This situation may partly account for the slightly higher risk of pneumonia with use of atypical antipsychotic drugs as compared to typicals, as demonstrated in some studies.

\section{Protopathic Bias}

Severe pneumonia may induce delirium requiring antipsychotic drug use in elderly patients [20]. In such a situation, the occurrence of pneumonia may be mistakenly attributed to the exposure to antipsychotics (ie, protopathic bias [21]). To explore whether the association between antipsychotic drugs and pneumonia was distorted because of protopathic bias, Trifirò et al. [9*•] performed an analysis excluding all patients who began the treatment within 7 days before the index date, which was considered as the first symptom of pneumonia registered in the medical records (ie, fever, dyspnea, other respiratory signs and symptoms).
To inspect the presence of the same bias, Knol et al. $[10 \bullet \cdot$ conducted an exploratory analysis removing those patients with any manifestation of delirium (ie, new prescription of benzodiazepine, and antibiotic use before hospital admission).

The sensitivity analyses confirmed the main results in both studies, thus excluding a major role for the protopathic bias in the observed increased risk of pneumonia in association with atypical and typical antipsychotics.

\section{Biologic Plausibility}

Regarding the increase in the risk for pneumonia with the use of typical and atypical antipsychotics in frail elderly patients, several potential biologic explanations have been hypothesized. However, the possible mechanisms of antipsychotic-induced pneumonia remain speculative.

Aspiration is a well-known pathogenic mechanism for CAP in elderly people, who are frequently affected by swallowing disorders and decreased cough reflex [22, 23]. It has been suggested that the use of typical antipsychotic drugs may be a risk factor for aspiration pneumonia, as a result of extrapyramidal effects $[9 \cdot \bullet$. Blocking of dopamine receptors may result in dyskinesia of the oral pharyngeal musculature, rigidity, and spasm of the pharyngeal musculature, which can result in dysphagia and ultimately in aspiration. Several case reports of antipsychotic-induced dysphagia have been described for both atypical and typical agents [24-30].

On the other hand, compared to typical agents, the risk for extrapyramidal adverse events with atypical antipsychotics is generally much lower, particularly when used at low doses [31-33], as is often the case in elderly patients [9••]. Thus, the greater risk for pneumonia with atypical antipsychotics than typical antipsychotics, which was observed in some observational studies, suggests that mechanisms other than extrapyramidal adverse events may play a major role. The anticholinergic action and histamine-1 (H1)-receptor blocking effect of antipsychotic drugs have been proposed as alternative explanations for the occurrence of pneumonia [10••]. The anticholinergic effect of antipsychotic drugs could lead to aspiration pneumonia through dryness of the mouth and impaired oropharyngeal bolus transport.

Excessive sedation as a result of H1-receptor blocking in the central nervous system is a well-known cause of swallowing problems, which could facilitate aspiration pneumonia in frail elderly patients, as a result of impaired laryngeal reflexes [34]. In accord with this hypothesis, Trifirò et al. [9••] documented a significantly increased risk for pneumonia with antipsychotics having the highest affinity to H1-receptor (atypical antipsychotics and phenothiazines) as compared to those with the lowest affinity (butyrophenones). This finding would support the hypothesis 
that the antihistaminergic effect of antipsychotics may play a major role in the occurrence of antipsychotic-induced pneumonia.

Finally, some authors suggested that antipsychotics may lead to pneumonia from direct or indirect effects on the immune system, which has been specifically documented for some compounds [35]. Agranulocytosis, a severe neutropenia that may increase the risk of infections, is a well-known adverse drug reaction of clozapine, even though it occurs in less than $1 \%$ of treated patients. Recent evidence suggests that all the other atypical antipsychotics and some typical antipsychotics can induce neutropenia but, in contrast to clozapine, this neutropenia very rarely progresses to agranulocytosis [36]. In a US cohort of 11,555 clozapine users in whom a weekly white-cell count was required to receive a supply of the drug, most of the cases of agranulocytosis occurred within the first 3 months of the treatment [37]. This finding seems to contrast with the very high risk for pneumonia during the first week of antipsychotic treatment, as observed in two studies [9••,10].

To summarize, it is likely that antipsychotics induce aspiration pneumonia in frail elderly patients through multiple possible mechanisms. Extrapyramidal adverse events, dysphagia, and sedation as a result of dopamine, cholinergic receptors, and $\mathrm{H} 1$ receptors may all play a role in antipsychotic-induced pneumonia.

\section{Recommendations for Clinicians}

Appropriate and judicious use of antipsychotic drugs may dramatically improve the quality of life and functional status of many psychiatric patients [38]. However, antipsychotic drugs are often misused and overused, especially in the elderly population, and in recent years, this inappropriate use of antipsychotics has resulted in several safety concerns. Current scientific evidence supports an association between use of antipsychotics in community-dwelling elderly and development of CAP in a dose-dependent manner soon after the beginning of treatment. For this reason, clinicians who start treatment with antipsychotic drugs should closely monitor elderly patients, particularly at the early phases of therapy and with high doses. If pneumonia-related signs and symptoms are identified, the withdrawal of antipsychotic treatment should be considered. In general, the lowest possible dose of antipsychotics should be prescribed. Whenever possible, concomitant administration of antipsychotics with other neuropsychiatric drugs having a sedative effect (ie, opioids, benzodiazepines) or anticholinergic properties (ie, antidepressant tricyclics) should be discouraged or limited to short periods with careful observation, because these drugs are additional risk factors for aspiration pneumonia in frail elderly patients.
Because pneumonia seems to be a frequent cause of death in elderly demented patients who are treated with antipsychotics, clinicians should very cautiously prescribe antipsychotics in these patients.

The risk for pneumonia may vary across different antipsychotics, but information about the risk for individual compounds is very limited. Hence, at this time, the risk for pneumonia in elderly patients should be considered when prescribing any antipsychotic medication.

\section{Conclusions}

Antipsychotic-associated CAP (probably aspiration pneumonia) seems to be a clinically relevant issue in frail elderly patients, as consistently documented in several epidemiologic investigations. No clear evidence exists for an increased risk of pneumonia in younger patients treated with antipsychotics. In elderly populations, the increase in risk is dose-dependent, and is more pronounced in the early phases of treatment with either typical or atypical antipsychotics.

On the basis of significant differences in the receptor binding profile of individual antipsychotics, heterogeneity in the risk for pneumonia among various compounds is suggested. Extrapyramidal adverse events, sedation, and dysphagia as a result of the antipsychotic action at dopamine, H1 receptors, and cholinergic receptors, are risk factors that may all play a role in antipsychotic-induced pneumonia. Future studies should better define the mechanism underlying antipsychotic-induced pneumonia and identify subgroups of antipsychotic users at higher risk of developing pneumonia.

Disclosure Conflict of interest: G. Trifirò-none.

Open Access This article is distributed under the terms of the Creative Commons Attribution Noncommercial License which permits any noncommercial use, distribution, and reproduction in any medium, provided the original author(s) and source are credited.

\section{References}

Papers of particular interest, published recently, have been highlighted as:

- Of importance

•• Of major importance

1. Trifirò G, Spina E, Brignoli O, et al. Antipsychotic prescribing pattern among Italian general practitioners: a population-based study during the years 1999-2002. Eur J Clin Pharmacol. 2005;61:47-53.

2. - Trifirò G, Sini G, Sturkenboom MC, et al. Prescribing pattern of antipsychotic drugs in the Italian general population 2000-2005: a 
focus on elderly with dementia. Int Clin Psychopharmacol 2010;25:22-8. Like US and Canadian studies, this Italian drug utilization study showed that the safety warnings (including that one about increased risk of fatal pneumonia) launched by regulatory agencies had an impact on the antipsychotic prescribing pattern. In addition, this study documented that antipsychotics were still widely used in elderly Italian patients.

3. Ashcroft DM, Frischer M, Lockett J, Chapman SR. Variations in prescribing atypical antipsychotic drugs in primary care: crosssectional study. Pharmacoepidemiol Drug Saf. 2002;11:285-9.

4. Hermann RC, Yang D, Ettner SL. Prescription of antipsychotic drugs by office-based physicians in the United States, 1989-1997. Psychiatr Serv. 2002;53:425-30.

5. - Trifirò G, Spina E, Gambassi G. Use of antipsychotics in elderly patients with dementia: do atypical and conventional agents have a similar safety profile? Pharmacol Res 2009;59:112. This review discusses all the recent safety warnings concerning the use of antipsychotics and the current evidence on the safety profile of atypical and typical antipsychotics in elderly demented patients. A specific paragraph addresses the risk of fatal and nonfatal pneumonia.

6. U.S. Food and Drug Administration: Public Health Advisory: Deaths with Antipsychotics in Elderly Patients with Behavioral Disturbances. Silver Spring, MD: U.S. Food and Drug Administration; 11 April 2005. Available at www.fda.gov/Drugs/DrugSafety/PublicHealth Advisories/ucm053171.htm. Accessed 12 October 2010.

7. •- U.S. Food and Drug Administration: FDA requests boxed warnings on older class of antipsychotic drugs [news release]. Silver Spring, MD: U.S. Food and Drug Administration; 16 June 2008. Available at www.fda.gov/NewsEvents/Newsroom/PressAnnouncements/2008/ ucm 116912.htm. Accessed 12 October 2010. This warning was launched by the Food and Drug Administration to inform health professionals about a similarly increased risk of all-cause mortality (pneumonia was one of the most frequently reported causes of death) with typical antipsychotics. This alert represents an extension of the previous warning concerning the same risk in association only with atypical antipsychotics.

8. van der Steen JT, Mehr DR, Kruse RL, et al. Predictors of mortality for lower respiratory infections in nursing home residents with dementia were validated transnationally. J Clin Epidemiol. 2006:59:970-9.

9. •- Trifirò G, Gambassi G, Sen EF, et al. Association of community-acquired pneumonia with antipsychotic drug use in elderly patients: a nested case-control study. Ann Intern Med 2010;152:418-25. This observational study provides new insight about the risk of fatal and nonfatal pneumonia in association with antipsychotic drugs in elderly patients. Possible biological explanations for the observed increased risk of pneumonia with antipsychotics are proposed and explored.

10. • Knol W, van Marum RJ, Jansen PA, et al. Antipsychotic drug use and risk of pneumonia in elderly people. J Am Geriatr Soc 2008;56:661-6. This article describes the first observational study that explored specifically the risk for hospitalized pneumonia in association with antipsychotic use in elderly patients.

11. Gau JT, Acharya U, Khan S, et al. Pharmacotherapy and the risk for community-acquired pneumonia. BMC Geriatr. 2010;10:45.

12. Star K, Bate A, Meyboom RH, Edwards IR. Pneumonia following antipsychotic prescriptions in electronic health records: a patient safety concern? Br J Gen Pract. 2010;60:e385-94.

13. Barnett MJ, Perry PJ, Alexander B, Kaboli PJ. Risk of mortality associated with antipsychotic and other neuropsychiatric drugs in pneumonia patients. J Clin Psychopharmacol. 2006;26:182-7.

14. Wang PS, Schneeweiss S, Setoguchi S, et al. Ventricular arrhythmias and cerebrovascular events in the elderly using conventional and atypical antipsychotic medications [Letter]. J Clin Psychopharmacol. 2007;27:707-10.
15. McElroy SL, Nelson EB, Welge JA, et al. Olanzapine in the treatment of pathological gambling: a negative randomized placebo-controlled trial. J Clin Psychiatry. 2008;69:433-40.

16. Roth BL, Meltzer HY, Khan N. Binding of typical and atypical antipsychotic drugs to multiple neurotransmitter receptors. Adv Pharmacol. 1998;42:482-5.

17. Salas M, Hofman A, Stricker BH. Confounding by indication: an example of variation in the use of epidemiologic terminology. Am J Epidemiol. 1999;149:981-3.

18. Walsh JS, Welch HG, Larson EB. Survival of outpatients with Alzheimer-type dementia. Ann Intern Med. 1990;113:429-34.

19. Jano E, Johnson M, Chen H, Aparasu RR. Determinants of atypical antipsychotic use among antipsychotic users in community-dwelling elderly, 1996-2004. Curr Med Res Opin. 2008;24:709-16.

20. Marrie TJ. Community-acquired pneumonia in the elderly. Clin Infect Dis. 2000;31:1066-78.

21. Horwitz RI, Feinstein AR. The problem of "protopathic bias" in case-control studies. Am J Med. 1980;68:255-8.

22. Marik PE, Kaplan D. Aspiration pneumonia and dysphagia in the elderly. Chest. 2003;124:328-36.

23. Riquelme R, Torres A, El-Ebiary M, et al. Community-acquired pneumonia in the elderly: a multivariate analysis of risk and prognostic factors. Am J Respir Crit Care Med. 1996;154:1450-5.

24. Stewart JT. Reversible dysphagia associated with neuroleptic treatment. J Am Geriatr Soc. 2001;49:1260-1.

25. Sagar R, Varghese ST, Balhara YP. Dysphagia due to onzapine, an antipsychotic medication. Indian J Gastroenterol. 2005;24:37-8.

26. Nair S, Saeed O, Shahab H, et al. Sudden dysphagia with uvular enlargement following the initiation of risperidone which responded to benztropine: was this an extrapyramidal side effect? Gen Hosp Psychiatry. 2001;23:231-2.

27. Bashford G, Bradd P. Drug-induced parkinsonism associated with dysphagia and aspiration: a brief report. J Geriatr Psychiatry Neurol. 1996;9:133-5.

28. Hinkes R, Quesada TV, Currier MB, et al. Aspiration pneumonia possibly secondary to clozapine-induced sialorrhea. J Clin Psychopharmacol. 1996;16:462-3.

29. Sliwa JA, Lis S. Drug-induced dysphagia. Arch Phys Med Rehabil. 1993;74:445-7.

30. Sokoloff LG, Pavlakovic R. Neuroleptic-induced dysphagia. Dysphagia. 1997;12:177-9. Stewart JT. Dysphagia associated with risperidone therapy. Dysphagia 2003;18:274-275.

31. Wada H, Nakajoh K, Satoh-Nakagawa T, et al. Risk factors of aspiration pneumonia in Alzheimer's disease patients. Gerontology. 2001;47:271-6.

32. Pierre JM. Extrapyramidal symptoms with atypical antipsychotics: incidence, prevention and management. Drug Saf. 2005;28:191208.

33. Jeste DV, Rockwell E, Harris MJ, et al. Conventional vs. newer antipsychotics in elderly patients. Am J Geriatr Psychiatry. 1999;7:70-6.

34. Schindler JS, Kelly JH. Swallowing disorders in the elderly. Laryngoscope. 2002;112:589-602.

35. Pollmacher T, Haack M, Schuld A, et al. Effects of antipsychotic drugs on cytokine networks. J Psychiatr Res. 2000;34:36982.

36. Rettenbacher MA, Hofer A, Kemmler G, Fleischhacker WW. Neutropenia induced by second generation antipsychotics: a prospective investigation. Pharmacopsychiatry. 2010;43:41-4.

37. Alvir JM, Lieberman JA, Safferman AZ, et al. Clozapine-induced agranulocytosis. Incidence and risk factors in the United States. N Engl J Med. 1993;329:162-7.

38. Alexopoulos GS, Streim J, Carpenter D, Docherty JP. Expert consensus panel for using antipsychotic drugs in older patients: using antipsychotic agents in older patients. J Clin Psychiatry. 2004;65 Suppl 2:5-99. 